\title{
Mainstreaming gender in the public service, developing conducive spaces
}

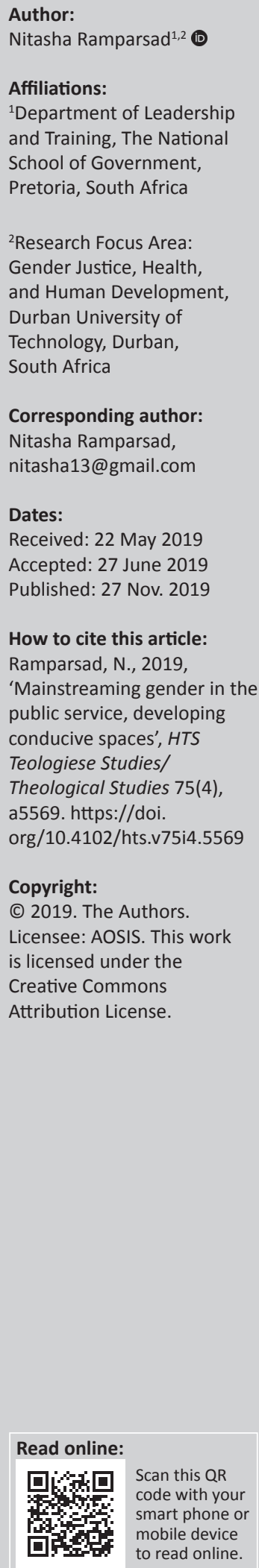

'Looking beyond Compliance' assesses the role of an enabling environment as a major factor in the successful mainstreaming of gender. This article analyses the important role of political will in influencing the creation of an enabling environment. The article suggest that several role-players need to possess the political will to ensure that an enabling environment is created. Notably, the actions of an individual have an impact on the institutional reforms developed and vice versa. Political will is argued as the most influential component in the development of an enabling environment and therefore creates the enabling environment through political buy-in. The argument specifically looks at the Department of Public Service and Administration located in the South African public service.

Keywords: gender mainstreaming; equality; enabling environment; South Africa; public service.

\section{Introduction}

This article analyses the role of an enabling environment as a factor in the successful mainstreaming of gender for gender equality in the Department of Public Service and Administration in South Africa. Gumede (2008) claims that in post-apartheid South Africa:

Significant challenges facing the democratic government included rebuilding the institutional mechanisms and initiating and implementing legislation and policies that are in line with the Constitution to usher in a new era of a developmental State. (p. 10)

Gumede (2008) speaks about the important role of an enabling environment in facilitating the implementation of gender mainstreaming in the public service. This aspect is crucial to ensure gender mainstreaming implementation in various departments of government.

Ultimately, Gumede's (2008) assessment of what he deems the post-apartheid South African civil service is a summation of the existing state of gender mainstreaming policy implementation barriers. The major focus of this article is on the role of an enabling environment in ensuring the successful rollout of the two key projects in the Department of Public Service and Administration, namely, the Gender Mainstreaming Project (GMP) and the 8-Point Principle Plan.

The GMP is a skills project aimed at capacitating public service officials working in the area of gender mainstreaming as a core function (namely, Gender Focal Points and Human Resource Directorates) and also extends to targeting senior managers whose responsibility is to mainstream gender into operations. The 8-Point Principle Plan is a guide for Director-General (DGs) to ensure that these principles are mainstreamed into the operations of their respective departments. ${ }^{1}$

The enabling environment is assessed in terms of the prioritisation and participation of Senior Management Services (SMS) and operational staff in driving the gender agenda in the Department of Public Service and Administration, the availing of resources (both human and financial) and the support from external structures to the operations of the Department of Public Service and Administration in mainstreaming gender. These criteria are measured through an analysis of reports generated for both projects as well as through testimonies of relevant staff members in the Department of Public Service and Administration. In addition, the creation of an enabling environment is also assessed as it relates to external support for gender mainstreaming, such as the National Gender Machinery, the Department of Women and the Commission for Gender Equality.

1.See http:www.dpsa.gov.za.

Note: Special Collection Gender Justice, Health and Human Development, sub-edited by Cheryl Potgieter (Durban University of Technology) 


\section{Defining the term 'enabling environment'}

The enabling environment is inextricably linked to the overriding factor of political will. Without the political will and buy-in from key role-players both within and outside the Department of Public Service and Administration, the success of the gender projects is unachievable. Here the institutional environment is assessed through the demonstrated commitment from operational staff and senior management, the availing of resources (both human and financial) by senior management and the support from external structures to the mainstreaming of gender in the Department of Public Service and Administration through the successful implementation of the GMP and 8-Point Principle Plan. The institutional environment in the Department of Public Service and Administration is in a state of flux, with constant restructuring and re-allocation of political heads, namely, the Minister of Public Service and Administration and the Head of the Department, the DG.

The fluid nature of the political environment has a major role in the construction of an enabling environment. As is evident from testimonies that will be discussed in this article, the appointment of a progressive minister is critical to the success of the gender projects in the Department of Public Service and Administration and, in my opinion, is a major influencing factor for the rollout and implementation of any policy put forward in government. The political will of internal actors plays a major role in the success of projects as the operational staff must possess the political will to ensure the success of their projects. The latter, as is evident from the testimonies featured, is a critical success factor as the commitment of project staff ensures that at least some, if not all, objectives of the existing gender projects are met to some extent in the Department of Public Service and Administration. Without this political will of internal actors, and with only a reliance on political heads, the projects will ultimately be ineffectual.

Giacchino and Kakabadse (2003:150) have identified two dimensions of location. The first dimension is regarding the individual who has to assume the responsibility for policy initiative. The second dimension is institutional and is concerned with decisions regarding the organisation. These two dimensions are critical in the implementation of policy as the analysis reflects the important role of the implementer within an institution.

These two dimensions are evident in the implementation of the GMP and the 8-Point Principle Plan as there is a distinct connection between the individual and the institution in the implementation of policy initiatives.

The individual and the organisation have a strong interplay in terms of the responsibility for the rollout of the gender projects. Both are inter-dependent and must be viewed as instrumental in achieving mutual success.

In the case of the implementation of the Tanzanian Community Health Fund Policy (Kamuzora \& Gilson 2007):
... [I]t was clear that the implementers influence how policies are experienced and how their impact is achieved. The apparently powerless implementers, at the interface between bureaucracy and citizenry, are difficult to control because they have a high margin of discretion and consequently re-interpret and reshape policy in unexpected ways. In some instances, implementers may react against efforts to impose policy change on them. The support of the implementers is therefore critical to the success of a specific policy, or its lack of success. (p. 95)

Political will has a significant role in the availing of tools for the successful mainstreaming of gender. The power dynamics in the Department of Public Service and Administration and in the culture of the South African state creates barriers for the implementation as the departmental staff members are bound by the bureaucracy of the system. The staff cannot overcome their barriers without the approval of seniors.

This becomes more complex when one considers the need to work with actors outside the Department of Public Service and Administration in the implementation of the gender projects. Notably then, power is ultimately regulated by bureaucracy as employee 'titles', and ultimately ranks, enable or disable the success of gender projects and projects generally in state departments.

Dror (1975) offers some thoughts on policy implementation and the role of an enabling environment. Dror (1975) claims that public policy tends to be precedent-based rather than goal-oriented:

However, goal-opaqueness can reduce conflict and promote consensus by enabling the public participants to adjust and interpret the objectives to suit themselves, hence ascertaining the acceptability of policy. (p. 60)

Dror (1975) further discusses the critical role of policymakers:

Policy-makers may prefer not to compromise themselves and may avoid explicit policy on controversial questions. Decisions are vague and are taken on an ad-hoc basis. Although this affects long-term planning, yet it facilitates intellectual and political tension in the system. (p. 80)

There is often a resistance to change as has been described by Dror (1975:80):

... [T] his is because policy actors tend to cling to common ways and to resist change, since the outcomes of new public policies are not always predictable. Also, there are vested interests in the status quo which involve a compromise between participants. (p. 75)

Despite all these deficiencies and weaknesses of the policymaking system in public participation, it is possible to improve some of them, and the extent to which this can be realised will be explored in the conclusions and recommendations section. Notably, transformation initiatives are at the mercy of those in senior management and thus true transformation cannot be effected without the political buy-in required.

Mannell (2012:52), in her discussion on the barriers to implementing gender policy, suggests an argument that 
resistance to social change is a major stumbling block in the plethora of barriers that face gender mainstreaming. She argues that because of a masculinist culture, gender is not prioritised in organisations. This perception shapes gender projects within the organisation. Notably, this point speaks about the broader focus of this article in the creation of an enabling environment. With the prevailing patriarchy, an enabling environment for gender mainstreaming cannot be achieved. Mannell (2012:52) further states that ' $[t]$ his ultimately impacts on the distribution of resources to those individuals or communities the organisation is trying to help'.

A huge failing is the assumption that an organisation is a gender-neutral space. Rao and Kelleher (2005) claim that gender inequalities are ignored in development work. They argue that development practitioners incorrectly perceive organisations as gender-neutral spaces. Gender work is viewed as something separate and not embedded (Tiessen 2007). The projects being delivered by the Department of Public Service and Administration in the rollout of the 8-Point Principle Plan and the GMP essentially seek to challenge the gender stereotypes and patriarchal notions in government.

Transformation is met with resistance from departments attempting to implement gender mainstreaming as a strategy for gender equality. Resistance, however, can be overcome through the influence of politicians as can be seen with the experience of the department in 2008, as shared by Roanne. ${ }^{2}$ The presence of a progressive minister who pushed the gender agenda was notable in the implementation of the project in the same year. With the change of minister, political will became poor at departmental head level as well as within the department. This is noteworthy as it speaks about the interplay between political will and the enabling environment. When asked about the factors that enable gender to be mainstreamed in the department, interviewee Roanne said:

The Minister at the time, Honourable Geraldine Fraser-Moleketi, was the driver of this (gender) agenda. Her openness to champion the gender work assisted in making the gender initiatives happen. The former Minister would discuss this with the cabinet colleagues and hence create buy-in at a very senior level. This meant that at cabinet level gender mainstreaming was discussed. In terms of resources, funding was not made available; human resources were not readily availed either, the Diversity Management Unit was expected to make this happen on our own. The political buy-in however made it easier to rollout projects through the Diversity Management unit and the then, PALAMA through the GMP. Currently, due to what I feel are competing priorities, gender mainstreaming is now shelved.

Mannell (2012:53) claims that staff training was identified as the major method to ensure that gender mainstreaming would be effected. These, however, are not the lived experiences of Gender Focal Points and the departmental staff. Rao and Keller (2005) argue:

All approaches to bringing about gender equality must have a political component. This is because gender relations exist within a force field of power relations, and power is used to maintain existing privilege. (p. 59)

2.Pseudonym.
Their assessment looks at the role of power relations in (dis) abling the environment for gender maisntreaming and therefore creating a major stumbling block for the effective mainstreaming of gender projects. The power relations associated with gender equality initiatives are often alluded to, and the power relations influencing the mainstreaming of gender are very evident in regulating how gender is prioritised in the Department of Public Service and Administration.

The sentiment on power relations is echoed by Goetz (1997), who says:

The social relations embedded in social institutions and development organisations cannot be changed just by getting a structural blueprint right - in the end, it is a matter of political struggle. (p. 28)

Thus, social relations in an organisation cannot simply be circumvented by training. Training is therefore only one element that may bring about a mind shift and therefore a possible change in the environment in which practitioners operate.

The GMP attempted to provide training to close the skills gap identified in 2006. Notably, the Public Administration Leadership and Management Academy $(2013)^{3}$ reflected that training can only be one aspect to address in the large context of gender mainstreaming initiatives in public service departments. A large part of the report's findings centres on the need of political will to access resources both internal and external to a department, as well as the need for an enabling environment where initiatives are developed yet not well received (Gender Mainstreaming Final Evaluation Report 2013). Here it is noted that skills training is only one aspect of the solution. In order to ensure that those skills are indeed implemented, political will is needed by the attendees' departments in unlocking the barriers to success, thus creating an enabling environment for the mainstreaming of gender into operations.

Mannell (2012) in her study on gender practitioners and the conflict over gender mainstreaming in South Africa claims that respondents in her study expressed that gender is 'invisible' in organisations:

The backlash against gender mainstreaming policy by organisations working on gender issues in South Africa has led in some cases to a rejection of gender policies for organisations. These organisations reject gender because of the way it has been adopted by other organisations in South Africa without critical reflection. (p. 148)

These observations mirror the experiences of the departmental staff in the rollout of the 8-Point Principle Plan and the GMP. Efforts to participate in these projects are often undertaken as compliance when addressing the 8-Point Principle Plan.

As explained in the interview with Roanne, the 8-Point Principle Plan is not largely supported by the department and is rather enforced through compliance reporting:

3.Internal document availed for the research article. 
The 8-Point Principle Plan emanated from the strategic framework, the department rolled this out through enforcing reporting. This was reinforced through conscientising departments through the rollout of advocacy workshops and then monitoring them through reports from departments. Here, the department is looking at challenges and an analysis of departments' challenges. This effort is ongoing until now, the unit supports the departments.

The compliance element attached to reporting is worth noting, as this speaks about an environment that may not necessarily be receptive or conducive to the mainstreaming of gender but rather focused on compliance reporting. The question of meaningful mainstreaming is raised. Ongoing support is still provided to departments 10 years after inception. This observation speaks about the need for more active leadership in departments in order to be able to take the 8-Point Principle Plan forward. With regard to the GMP, a large part of the enabling environment was influenced by the funded nature of the project. Therefore, practitioners and departments had minimal investment in the skills course in terms of monetary outlay. The only requirement was to complete the relevant portfolio to attain an accredited certificate. The investment however is noteworthy as attendance of the skills programme is evidence that these Gender Focal Points witnessed a gap in their skills set that needed to be closed. Enabling these skills, however, is what will ultimately unlock the gender barriers in their departments, and the latter is out of the control of the Department of Public Service and Administration.

The role of donors in creating enabling environments is a highly politicised area that must be looked at in order to close the critique of the (dis)enabling actors in the operationalisation of gender mainstreaming in the department. Eyben (2008) claims that:

The relationship between international development donors and the organisations they fund is a 'gift relationship' meaning that it is far easier for donors to promote policies that may have little relevance to the context for which they are intended. (p. 10)

This is an astute observation and is conspicuous by its absence in the Gender Mainstreaming Final Evaluation Report (2013). Mannell (2012) argues that:

The relationship between funding organisations and gender practice in South Africa needs to be interpreted through this dynamic. Bilateral donors may design policies that have more appeal to the national population to which they are accountable than for the recipient population. Power in the relationship is largely in the hands of the donor organisation to determine what the intervention should look like and how it should be carried out. Larger sums of money give donors even greater ability to influence organisational priorities and implementation practices. While funding structures do not provide the entire picture of the dynamics affecting the gender and development field in South Africa, they do offer a portion of the picture about which types of interventions are put into practice. (p. 37)

Notably, the final evaluation report is written by NB Ideas and Associates for Canadian International Development
Agency (CIDA). This observation clearly points out the blurred lines in being the proverbial player and referee. Recommendations made by the donor were sweeping and reflect no cognisance of the scope of work needed to implement the recommendations made and the extent to which each recommendation is by and large out of the control of the existing project staff and the department as a whole.

As part of the broad recommendations, the department was advised to ensure '... the requisite government machinery is in place to effect gender mainstreaming' (PALAMA - Gender Mainstreaming Final Evaluation Report 2013:5). This recommendation as discussed by the project staff is out of the scope of control of the department and is largely dependent on the actions of a completely separate ministry, namely, the Department of Women, as the key driver of the National Gender Machinery. Notably, a key recommendation by the final evaluation report points to the need of a closer engagement with CIDA as the funding agency (PALAMA Gender Mainstreaming Final Evaluation Report 2013):

More intensive donor engagement drawing on the lessons from other contexts and encouraging more holistic project logics, programmatic approaches and monitoring of impacts as part of the project monitoring process. (p. 5)

These recommendations echo the sentiments of Mannell (2012) in her assessment of the relationship between funders and a recipient organisation. To a large extent, PALAMA (now the National School of Government [NSG]) kept their autonomy in the rollout of the GMP; however, many reporting restrictions and scope creep affected the management of the project and is evident from the final evaluation report.

In the development of an enabling environment, Leftwich (1995) emphasises the role of politics. Political dynamics significantly impacts public policy. After all, the agenda of the public sector is set largely by politicians. In fact, Dror (1975:81) alludes to this when he argues that policy and politics 'closely interact, often overlap, and in part cannot be separated even analytically'. Other scholars, such as Stone (2001) and Persson and Tabellini (2002), have dealt with this issue in different contexts. These views are evident in the testimony presented by Roanne.

\section{Prioritisation and participation of senior management services in driving the gender agenda}

As noted earlier, the role of political will is a great influence in the uptake of the projects implementing gender mainstreaming as a strategy for gender equality. Interviews with project staff rolling out the GMP and the 8-Point Principle Plan indicate theneed for an enabling environment to ensureimplementation and the influence of political will in the creation thereof, as discussed below. Political will is expressed as political behaviour, and behaviour is influenced by various factors (Post, Raile \& Raile 2010). Many studies have confirmed that in the life of an individual, values and value systems represent 
the main influences in political behaviour (Knafo \& Schwartz 2001; Rokeach 1973; Schwartz 1996). Values possess the most influence on views and behaviours (Eysenck 1954; Rokeach 1973; Schwartz 1992). These are used as the criteria for evaluating people and events. Values are central in politics and political judgements as well as preferences. Schwartz (1992) defines political will as:

[I]deas or beliefs related to desirable goals or behaviours that go beyond specific situations, guide selection or evaluation of behaviour and events and which are hierarchically ordered by relative importance to an individual. (p. 4)

The behaviour of individuals ultimately influences the outcome of the gender projects in the department. This is evident from the testimonies of officials featured later in this article.

Interviewee Anna ${ }^{4}$ indicated that $[T]$ he biggest obstacle is management. Until such a time that the management of a department recognises gender mainstreaming as the key, we will not be able to make as good a progress as we should. It is noted that management has been identified as one of the key drivers of implementation in a department and therefore has a major influence on the development of an enabling environment. Interviewee Roanne commented:

'Despite having implemented gender mainstreaming training in departments over the years, there are managers who still regard gender mainstreaming as a 'nice to have' issue. Gender mainstreaming should be one of the key projects within departments and should be reflected in departments' Strategic and Annual Performance Plans but it is not yet happening. The primary focus in departments is the achievement of EE targets. Gender Mainstreaming is much more than numbers.'

Roanne's testimony speaks about the lack of prioritisation and support for the GMPs in the department. Brynard (2009) claims that although commitment as a factor is critical, it is not always clear what determines commitment. Studies into the performance of policy implementation have indicated the complex and dynamic nature of the subject matter. Investigations have constantly been plagued by the problem of too many variables (Goggin 1986:329). According to Goggin (1986):

... [T] hree clusters of independent variables can be identified. The first is the form and content of the policy itself. The second cluster is the capacity of the organisations responsible for making the policy work. The third cluster refers to the qualifications of the people in charge of policy operations. (p. 329)

The categories identified by Roanne are, however, not an end in itself. Again, the recognition of political will as a major influence on creating an enabling environment must be acknowledged.

\section{Interviewee Ardrie commented:}

'... [R]esponsibility is metered out too widely and invariably no one took responsibility (for gender mainstreaming). Incompetence in the Ministry means that there is no champion of gender 4.Pseudonym. mainstreaming in government.' (Former Commissioner of the CGE and current South African Gender expert)

These astute observations talk about the role of additional key players in the gender landscape and the lack of a key driver for the gender agenda in creating an enabling environment for the rollout of the GMP and the 8-Point Principle Plan. This comment also speaks about Goggin's wider debate on responsibility. Here it is noted that responsibility is in fact meted out too widely, resulting in no responsibility being taken up in any significant manner by state structures or government departments (Goggin 1986):

Implementation involves different behaviours in both the administrative and the political dimensions. The exact manner or style of implementation is a result of certain implementing decisions that shape implementation behaviour. The success or failure of implementation is due to behaviour during the course of implementation. (p. 330)

Interestingly, Goggin (1986:330) remarks that the process should be separated from the product. Thus, a distinction should be made between performance and consequence. This is noted in the experience of the trainees in the GMP. Essentially, attendance of the programme does not necessarily translate to successful performance. Each trainee faces barriers to implementation that are not within the control of the department. According to the PALAMA - Gender Mainstreaming Final Report (2013:40), attendance of the GMP by officials in the DOE in and by itself was insufficient to galvanise change because of barriers in their line department. This speaks about the needs of attendees of the programme to have an enabling environment to allow for implementation beyond a skills programme.

The PALAMA - Gender Mainstreaming Final Evaluation Report (2013:5) also reiterates the views of the Gender Expert cited earlier. The report most notably points to the wider machinery and the then Department of Women, Children and Persons with Disabiities (DWCPD), now known as the Department of Women. The PALAMA - Gender Mainstreaming Final Evaluation Report (2013) notes:

The GMP should be located within a broader gender mainstreaming strategy and programme, and as the Department of Women, Children and People with Disabilities holds the mandate around gender, it needs to create an enabling environment for gender to be mainstreamed. It is recommended that this should include: Locating the training in a broader gender mainstream programme; Coordinating all the stakeholders involved in gender work; and supporting the establishment of a community of practice. (p. 5)

The PALAMA - Gender Mainstreaming Project Evaluation Report (2013) calls for institutional reform, which has been echoed by interviewees. The institutional reform being called for points to the need of an enabling environment and the need of gender champions at departmental level who are at a senior level. The PALAMA - Gender Mainstreaming Project Evaluation Report (2013) also points to the role of the then DWCPD as being a major role-player in creating an enabling environment for the successful mainstreaming of gender: 
For the full impact of the course to be realised, the course needed to be an integral part of a much larger gender mainstreaming intervention. The scope of this falls outside of PALAMA's mandate. The DWCPD is the obvious lead for the broader initiative. (p. 24)

The evaluation also noted the importance of senior management attendance in developing an enabling environment for the sustaining of gender mainstreaming initiatives. The role of senior managers is highlighted as a key element in the effective implementation of gender mainstreaming initiatives in a department (PALAMA Gender Mainstreaming Project Evaluation Report 2013):

The Deputy Director for Social Cohesion and Equity in Education who said the course was very useful was careful to outline a 'disclaimer': 'At the level where I am, the course is ok to get the information, but we do not influence key decisions therefore it becomes frustrating ... It would be really useful if we were attending with senior people' namely Chief Director, Deputy DG and DG. (p. 27)

The report further explains the absence of senior managers from the process (PALAMA Gender Mainstreaming Project Evaluation Report 2013):

Several reasons were cited for the lack of senior management participation including a lack of political will, pressures on senior managers' diaries, a lack of buy-in from managers, the way the course is marketed, PALAMA's reputation amongst senior managers and a reluctance to participate in a course with more junior staff. These issues were picked up early on in the programme's delivery and various initiatives taken to mobilise senior managers. In the main, however, these were unsuccessful. (p. 27)

Again, the recurring theme of political will emerges. Political will is therefore a critical factor in creating an enabling environment. Notably, an enabling environment is greatly influenced by the need for the necessary structures within a department. In the analysis, the barriers to a department are discussed by the PALAMA Gender Mainstreaming Evaluation Report (2013):

Respondents spoke about their frustrations with the delay in operationalising the organisation's Gender Mainstreaming Strategy. Respondents noted that the first priority is to establish a Gender Focal Point and a Gender Mainstreaming Advisory and Compliance Committee. This recognition of the need for leadership and accountability is clearly set out in the Gender Mainstreaming strategy of the department ... In the absence of these structures the strategic push on gender is shared between the HR Department and the Gender Mainstreaming Project staff. Overall reflections on the lack of movement on setting up the internal gender structures give rise to strong feelings and perceptions that work on gender in the Department and are not that important. (p. 33)

The need for internal structures has been a recurring theme from those working in the gender arena within the public service. Mikkola and Miles (2007) claim that:

... [T] he exact characteristics of hierarchical gender valuations differ across countries, but there is no doubt that hierarchy itself exists to different degrees in most (one might argue, to some extent, in all) cultures. Its existence can be more vividly seen when looking at cultures in which practices differ from our own. (p. 37)

This argument is also reiterated by Kandiyoti (2002:17), [ $t]$ he appearance of patriarchy differs in Africa from the form of patriarchy in Muslim countries or Asia.

Generally, gender hierarchy is not necessarily implied by gender-specific specialisation, but rather by the restricted opportunities and restricted perspectives for the future that this specialisation typically carries with it. This specialisation or role might be culturally prescribed or taken on by individuals freely. Roanne, when asked on how to approach gender mainstreaming, stated:

'Political will is awkward to address, the talk does not necessarily translate to change. There is a male-dominated cohort being appointed at a senior level, the Ministers must take into consideration the achievement of equity targets. Political will must be addressed in order to address the gender parity in senior appointments. The role of cabinet must also be questioned for political will. When only males are recommended for appointment, there does not seem to be consideration of transformation. Have they thought about what the Women's Ministry is supposed to achieve, the Bill for gender equality is not publicised.' (Former Manager for Diversity portfolio at the Department of Public Service and Administration)

The response is noteworthy as it reiterates the link between an enabling environment and political will. It is also important to reflect on the role of patriarchy in creating the 'male-dominated cohort' as described above. This is a critical factor in the implementation of gender mainstreaming for gender equality. Notably, it is evident that a committed internal staff complement each other, are responsible for implementing the project and ultimately reflect their own political will in driving the project's success. The onus therefore cannot be directly placed on the shoulders of the SMS echelon. The small successes achieved through the GMP are clearly an indication of what can be achieved with political will from operational staff.

\section{The availing of human and financial resources in building an enabling environment}

The availing of both human and financial resources is important when assessing the development of an enabling environment for successful gender mainstreaming. Major gaps are discerned between policy and practice in the South African Beijing +20 Report. The report highlights the need for strengthening the enforcement of laws and policies in the country (UN 1995):

There is a clear gap between compliance requirements and measures implemented. Although the law prohibits gender and related forms of discrimination, women continue to experience systemic gender discrimination and inequality in all aspects of life and during all phases of their lifecycle, the worst being as girl children and elderly women. (p. 11; UN 1995) 
A major challenge identified in the report notes (South African Beijing +20 Report 2014):

Overall there is mostly an implementation of a combination of human rights and a basic needs approach to gender transformation in the country with most of its policies and programmes pointing to a leaning towards a basic needs approach. This meant that at times there was very little attention paid to the international compliance framework on women's human rights. (p. 14)

Here again, there is a direct analysis of the inability of the South African public service to adequately enforce the laws and policies on gender into its operations. Compliance requirements are not met and also attributed to the fact that attention is being paid to basic needs. The report forthrightly notes (South African Beijing +20 Report 2014):

At the implementation level, there is a general failure to systematically implement both gender mainstreaming and women empowerment. In general, decision-makers and implementers appear to be more comfortable with equity aspects of gender equality, as it relates to the 'numbers issue', where success sometimes is judged on a numbers only basis. Sometimes the agenda is narrowed to the issue of placing women in decision-making positions and occupational categories where they were historically excluded. (p. 14)

Furthermore, the Towards a 15 Year Review (2009) explains in its analysis of the barriers for the mainstreaming of gender policy and claims that:

... [W]hile these institutional arrangements for driving the issues of gender equality tend to be acknowledged internationally as best practice, closer to home one finds challenges in their operation. Chief among these is the matter of entrenched negative attitudes towards gender equality, lack of understanding and accountability to address this coherently, and inadequate mechanisms and resourcing, financially and in terms of human capacity, for effective implementation.

Resourcing is thus clearly affected by a lack of accountability and sustained leadership. This point links to the role of political will in driving an agenda for policy implementation. It is also noted that the analysis of the South African Beijing +20 Report (2014:14) equates the disparity with allocation of resources to the disparity in levels of appointment and location - and therefore authority - of gender focal persons, impacting the extent to which they can effect gender mainstreaming in government processes. Therefore, the authority level of a Gender Focal Point has a major role in the creation of an enabling environment for the mainstreaming of gender.

The availability of, and access to, resources for the use of gender mainstreaming for gender equality is also attributed to the lack of institutional mechanisms. The South African Beijing +20 Report (2014) praises public service interventions for the issue of quotas, the establishment of a National Gender Machinery and the subsequent elevation of the then the Office on the Status of Women was elevated to a Ministry:
The Department of Women, Children and People with Disabilities encountered challenges of inadequate resources - financial and human - resulting in failure to meet the expectation of women in the country. In this regard, following the National Election in May 2014, His Excellency President Zuma announced that this Ministry will become the Ministry for Women located in the Presidency. The Women's Ministry will champion the achievement of women's socio-economic empowerment and women's rights. This is a clear indication that the mandate on women empowerment and gender equality will receive better attention and support when it is located in the highest office in the land and be more authoritative over accountability by stakeholders in meeting the empowerment of women and the achievement of gender equality in the country. (p. 41)

The creation of an enabling environment is therefore absent from the key role-players identified by this report. The claims made herein are refuted by the lived experiences of Gender Focal Points and the various experiences cited by interviewees in their interactions with both the National Gender Machinery and the Department of Women. Anna, at the NSG, when asked about her major challenges in implementing GMP rollout commented that:

'The biggest obstacle is management. Until such a time that the management of a department recognises gender mainstreaming as key, we will not be able to make as good a progress as we should. Despite having implemented gender mainstreaming training in departments over the years, there are managers who still regard gender mainstreaming as a 'nice to have' issue. Gender mainstreaming should be one of the key projects within departments and should be reflected in departments' Strategic and Annual Performance Plans but it is not yet happening. The primary focus in departments is the achievement of EE targets. Gender mainstreaming is much more than numbers.' (Former staff member of the Gender Mainstreaming Project)

As has been discussed earlier, the funded nature of the GMP was a noteworthy factor in the success of the project rollout. The enabling environment for the uptake of the course was therefore influenced by resource availability. The Department of Public Service and Administration has taken a strong stance in creating a receptive environment for the rollout of the 8-Point Principle Plan. The former Chief Director of the Diversity Management Unit when asked about the role of the department in creating an enabling environment for the mainstreaming of gender commented that:

'The 8-Point Principle Plan emanated from the strategic framework, the Department rolled this out through enforcing reporting. This was reinforced through conscientising departments through the rollout of advocacy workshops and then monitoring them through reports from departments. Here the Department is looking at challenges and an analysis of departments' challenges. This effort is ongoing until now, the unit supports the departments.'

These efforts are to be commended as they reflect the role of the department in attempting to develop an enabling environment through availing resources for the implementation of the 8-Point Principle Plan. Roanne counters the availing of resources for the delivery of training on the GMP and 8-Point Principle Plan with her assessment of the rollout: 
'Critical involvement by the former PALAMA, now NSG, in the imparting of skills is very important in creating a common understanding of gender mainstreaming in the public service. The main challenge experienced (in my opinion) was the accredited status of the programme; this created a barrier for some learners. People are reluctant to submit a portfolio. An informal strategy could go a long way in addressing this, in making the course more accessible. The course could be reframed to target different groups such as the Gender Focal Points separate to those working outside of this space.'

The inputs by Roanne are of importance as they speak about the lived experiences of Gender Focal Points in developing an enabling environment for not only implementation but also access to the tools for implementation. Therefore, resource availing for training is but one element for the successful creation of an enabling environment.

\section{External structures}

The role of external structures in the development of an enabling environment in the Department of Public Service and Administration is necessary to provide a complete picture of the support provided to the implementation of the GMP and the 8-Point Principle Plan. The department cannot achieve the success with the rollout of the gender projects without the assistance and support of the external structures responsible for the mainstreaming of gender in the South African state. The First Inaugural Gender Indaba Report (2008) highlighted the need for an enabling environment before the formal rollout of the GMP and the 8-Point Principle Plan. A major obstacle identified by the Indaba report was the need for an enabling environment. One of the key solutions was, ' $[a] 11$ Departments should create an enabling environment for individuals to report harassment' (First Inaugural Gender Indaba Report 2008:25).

Notably, a major challenge with female managers was that '[f]emale managers do not take responsibility for their own enabling environment'. The report, however, is silent on how these barriers would be overcome and the role of male managers in supporting the process. The report appears to suggest that female managers are responsible for the development of their environment and fails to acknowledge the role of patriarchy and the macho culture of the state. An overarching suggestion that an enabling environment must be created was not useful for implementing departments as it did not provide the concrete details as to how this would be undertaken and, importantly, who would lead this. The report should be revised to include a clearer strategy on the major role-players and how the appointment of women to senior management is only the beginning of a change. For change to be sustained, systemic change must be addressed and all processes within departments must be addressed to incorporate a gender lens.

The South African Beijing +20 Report (2014) clearly notes the importance of this factor in the successful mainstreaming of gender for gender equality:
There is a particular highlight with regard to de jure equality or equality in the eyes of the law, where law reform has seen to the removal of various discriminatory laws and enactment of laws that foster an enabling environment for the advancement of women and the achievement of gender equality. With regard to de facto equality, significant progress has been made but there is still much to be done especially with the full and effective implementation of laws, policies and strategies. (p. 7)

The report notes a move beyond policy and a focus on implementation. An enabling environment is highlighted as a major factor in enabling gender to be effectively mainstreamed. Interestingly, the South African Beijing +20 Report is hailed as a national review. The report, whilst commenting on an enabling environment, goes further to note (UN 1995):

One of the key successes on women empowerment and gender equality has been the creation of an enabling environment through favourable laws, policies and encouraging informal policy pronouncements. One of the key policy instruments in this regard is the NPF for Women's Empowerment and Gender Equality (2000) adopted by the South African Government. This Gender Policy Framework sets the tone in the country for gender mainstreaming across all sectors of society while at the same [time] adopting an approach for women's empowerment and gender equality. It furthermore outlines the National Gender Machinery to support gender transformation as well as priorities and structural arrangements towards women's empowerment and gender equality in the country. (p. 23)

The inclusion of these comments in the South African Beijing +20 Report provides loaded statements and is refuted through interviewees and implementation reports in the Department of Public Service and Administration. The barriers to effective implementation are related to various factors, one of which, as has been noted before, is the inability of the National Gender Machinery to support gender transformation in the public service. The currently non-functional National Gender Machinery creates an implementation void. Many partners are affected by the absence of the National Gender Machinery and the lack of accountability by the Department of Women in ensuring that the National Gender Machinery is led and managed well.

As mentioned earlier, the PALAMA - Gender Mainstreaming Project Evaluation Report indicated that the Department of Women, Children and Persons with Disabilities, now known as the Department of Women, is the obvious lead to create institutional reform. In the absence of resources being availed by the relevant ministry, PALAMA, now the NSG, has availed resources for the GMP. In this case, the staff, trainers and gender experts made these available through donor funding. The 8-Point Principle Plan has a greater reliance on political will in order to drive its agenda. This has not been institutionalised into DGs' performance agreements because, and at such time, the departmental efforts are limited to the SMS Women's Round Table hosted once a year in August under the theme of Women's Month. Resource allocation and availability in terms of finance and/or other factors are therefore inextricably linked to the political will of an 
organisation, which again is also a great influence to create an enabling environment (PALAMA-Gender Mainstreaming Project Evaluation Report 2013):

Mainstreaming gender requires change at every level of an organisation; a transformation which requires dedicated capacity and time to drive the change agenda. Developing policies, strategies and other resources are important but only really effective if they are tools in a larger process of change that tackles the organisational culture, individual behaviour, and programme and project outcomes. Where participants were able to galvanise a broader support base which included leadership, more change was possible. (pp. 43-44)

Thus, most significantly it is noted that there is a distinct interplay between resource availability and support from external structures in creating an enabling environment. Resource allocation is not the only answer to the complexity of gender projects in the South African state. The evaluation report points to the need for a change in behaviour, which will in effect lead to a change in organisational culture and will enable more support for the rollout of gender projects. The availing of resources must therefore be linked to these elements to be successful. In this article, it is revealed that all elements are in fact influenced by political will and that this overarching factor is indeed the key to the success of gender projects in the South African state.

Ardrie, ${ }^{5}$ when asked about the role of the National Gender Machinery in creating an enabling environment for the mainstreaming of gender for gender equality, commented that:
'A big problem in how the Act was written was that the Commission for Gender Equality (CGE) is accountable to Parliament but has oversight of government. Any interaction with civil society was dismissed in favour of Parliament. Public hearings were held on gender discrimination and such issues with the private and public sector, the problem was, however, with the departments. The CGE has no 'teeth' when a department does not want to implement. It may have the power to issue fines but falls flat when it comes to implementation. One of the four pillars to their mandate is to build the CGE. A lot of energies went into this and making policies on dealing with the organisation than a focus on the projects.'

The internal management issues, therefore, have also created a barrier to the effective functioning of the National Gender Machinery. The Commission for Gender Equality, being a key element of the National Gender Machinery, needs to be well functioning to also play its significant role in the mainstreaming of gender within the public service. The Commission for Gender Equality must therefore fulfil its role in the creation of an enabling environment. It is well positioned as a Chapter 9 institution outside of government to enable the mainstreaming of gender through 'neutral' interventions which would lead to holding the state accountable for the rollout of gender projects. The neutrality of the Commission for Gender Equality must be protected in order for this body to be effective.

5.Pseudonym.
The interviewee went further to comment on the need of the Commission for Gender Equality to play a leading role in the work of the department:

'The Commission for Gender Equality is like the public protector in the gender space. They must protect the rights of women in the workplace. Their focus must be on all sectors but they could be the watchdog for gender mainstreaming in the public service, for example, requesting reports on gender programmes, achievements, challenges, looking at offenders for sexual harassment/areas of concern that need to be flagged in the public service. The Commission for Gender Equality could play a more direct role in an evaluation role in producing knowledge, impact studies and advising departments on trends emerging from the evaluation reports. This could assist the Department in policy revision for implementation.'

Here it is noted that other role-players must take the lead in contributing to the creation of an enabling environment. External role-players are crucial to the success of the gender projects in the department as political will and buy-in is a central element. The department as the policy ministry can be successful to a point; however, the onus is on other departments to implement gender considerations into their operations.

As has been alluded to earlier, the gender components of the South African Constitution of 1996 represented a major accomplishment for those involved in the women's movement. The Constitution (Act 108 of 1996) guarantees equal and inalienable rights to men and women and instructs the government and civil society to uphold the values of equality. The Constitution specifically stipulates the creation of the CGE 'to promote respect for gender equality' and its 'protection, development and attainment' (1996, ss. 187). While the Commission for Gender Equality and government machinery for gender in South Africa represent a major change by the actors involved in fighting for women's rights, today the movement in South Africa is fragmented with little coordination between women's organisations. The blame for this is often put on the absorption of talented women activists into government positions with the launch of the ANC into power in 1994 (111 women became Parliamentarians in 1994), thus creating a 'vacuum' at the grassroots level (Geisler 2000:624).

Women's movements refer to alliances among women's organisations around issues of gender equality, while women's organisations refer to individual organisations. There exists heterogeneity of organisations, such as professional associations, networks and service providers (Tripp et al. 2008:13). The slow retreat of the Women's Movement according to Gouws (2005) is attributed to the sectoral organisation of women around issues such as health, domestic violence and notably comments on the impact of rural women on influencing the passing of certain legislation. This mobilisation was influenced by a decline in optimism and a degree of scepticism in the National Gender Machinery. Many women activists had been absorbed into government and this had a major impact on their 
effectiveness (Fester 1998). Furthermore, Hassim (2003) claims that the Women's Movement wanted equality in the norms and procedures of government and wanted to reduce a reliance on political will for the success of gender equality. This was not being met by the National Gender Machinery, and thus a retreat by the Women's Movement was perhaps inevitable in order to mobilise around key issues. See also Hassim (2006) in her analysis of the trajectory of women's organisations in South Africa.

The decline, however, was preceded by many critical actions to ensure gender mainstreaming occurred within the state. Gouws (2005:113) expands on the acceptance of the National Gender Machinery, ' $[t]$ he acceptance of the National Gender Machinery followed on a long and hard struggle by South African women to put gender on the agenda'. This work is currently largely unacknowledged by the department and is evident in the current focus on policy without any interest in engaging other sectors. In its current state, the Women's Movement is therefore not a clear network of organisations, but rather a few scattered organisations. The transfer of women activists to official government cannot only be seen as a loss to the South African Women's Movement. More questions need to be asked about the impact of these women leaders 24 years after democracy and their role in creating an enabling environment.

\section{Support from the non-governmental organisations sector in creating an enabling environment}

The Africa Regional Shadow (2009:38) notes that women are largely under-represented in decision-making process in the public service and from leadership positions even within tribal and/or traditional settings. The report also further addresses the lack of internal democracy within political parties. The non-governmental organisations (NGO) sector has historically had a large role in the gender agenda in South Africa. The South African Shadow Report on the implementation of UN (1979) reflects a strong emphasis on the need for the state to create enabling structural and societal conditions necessary to ensure that women can fully participate and exercise their relevant rights in the political, social, economic and cultural fields. The support from structures is critical for developing the necessary societal conditions for the implementation of gender projects. These structures are tasked with developing the necessary conditions, which include the availing of resources and the development and sustenance of political will that contribute to the development of an enabling environment.

Mannell (2012) discusses the role of 'actors' and notably extends this to include various organisations and individuals with mandates that relate to gender and development policy issues. She claims that in South Africa this is defined as practitioners and non-practitioners. The latter is referred to as the NGO sector (Mannell 2012:32). A key element of the
National Gender Machinery is membership by NGOs. The criteria for which selection and 'membership' are allowed are, however, not forthcoming although repeated attempts have been made to ascertain this information from the Department of Women. The criteria for membership, once availed, will explain how membership from the NGO sector is vetted. The inclusion of Faith-Based Organisations (FBOs) is also of interest as much work is undertaken by these organisations to enable the effective implementation of gender projects.

In South Africa, the NGO sector is made up of trusts, and Section 21 organisations (not-for-profit companies or associations that report budgets publicly). In 2010 and 2011, there were 76175 registered non-profit organisations (NPOs) in South Africa, $95 \%$ of which were voluntary organisations under the government's categories. Notably, Mannell (2012) notes the overburden on NGOs:

Gender is not an area of NPO practice according to the South African DSD categorisation scheme. Rather, gender is taken up within other areas of NPO practice including law, social services, development and housing, and health, making the actual number of organisations carrying out gender-related interventions in South Africa at one particular moment in time difficult to measure. (p. 32)

The burden of care, therefore, places a restriction on resources available for influence to gender mainstreaming alone whilst there are conflicting priorities. This observation may explain the lack of sufficient pressure from the NGO sector on the department to implement the 8-Point Principle Plan and the GMP. It is assumed that the absence of voices from the NGO and FBO sectors in the reports availed for this article is indicative of the absence of collaborations with these sectors.

According to an independent database for development organisations in South Africa, ${ }^{6}$ there are approximately 78 organisations (including NGOs, community-based organisations and FBOs) in South Africa currently listing gender as one of their programme areas, $2 \%$ of the total organisations registered in the database. Gender-focused organisations therefore appear to make up only a small number of the organisations working in the NGO sector in South Africa. They exist within a field where advocacy and politics, environment and religion are the dominant development sectors. Mannell (2012) suggests that the resource restrictions on NGOs in South Africa further constrain the ability of NGOs to influence the public service operations and thus to create an enabling environment (Mannell 2012):

NGOs often receive funds in order to carry out their work from a variety of sources. This includes multilateral and bilateral Official Development Assistance (ODA) and funding from multinational NGOs. The amount of funding provided to gender interventions in South Africa from multilateral ODA is limited. In the first instance because the majority of multilateral 6.See www.prodder.org.za. 
development assistance is allocated to 'low-income' states while South Africa is considered by the World Bank to be a 'middleincome' State. Secondly, there is no UNIFEM presence in South Africa, meaning that gender-related funding is primarily managed under the UNDP and largely restricted to achieving the SDGs outlined previously (i.e. funding from national development aid organisations and institutions). (pp. 33-34)

In the remainder of this section, I summarise the two other types of funding sources most relevant for gender mainstreaming and development practice in South Africa: multinational NGOs and bilateral donors. In addition to the funding available to the public service, routed through the Department of Treasury, there is a substantial amount of aid coming into South Africa and being routed to the NGO sector (Development Partnerships Survey 2014):

\section{Large multinational NGOs, CARE International and Oxfam in particular, provide large amounts of money to local organisational partners to carry out gender interventions in South Africa. CARE International reported spending USD263 million on programme activities across the African continent in 2010. Broadly, CARE focuses on providing support for community development projects. Gender-related funding provided by CARE in South Africa has focused on empowering women through 'local economic development' and 'voluntary savings and loans projects'; and strengthening civil society to deal with gender and rights issues. (p. 20)}

Oxfam is an international advocacy and humanitarian organisation that provided $\$ 275.1$ million to charitable projects in 2010 and 2011. Ten per cent of this amount $(\$ 27.5 \mathrm{~m})$ was allocated to 'equity' projects under which much of Oxfam's gender activities resort. Oxfam's emphasis on funding gender interventions in South Africa is on genderbased violence and women's political and economic leadership, whereas for CARE economic development for women and women's rights represent key priorities. There is some overlap between these strategic priorities.

Broadly, much of the funding for gender interventions from these multinational donor organisations is targeted at addressing women's economic empowerment, women's political leadership, and gender-based violence. (see www. care.org) Substantial funding being moved into NGOs, however, does not translate to a loud enough voice within the public service realms. The staff expressed that limited interactions were experienced with the National Gender Machinery, the Department of Women and the Commission for Gender Equality. The voice of the NGO sector is conspicuous by absence and must also be held accountable for the creation of an enabling environment for the mainstreaming of gender into public service operations.

The cohesiveness of the Women's Movement postdemocracy has had a great influence on its ability to adequately fulfil the role of public service watchdog for gender equality. McEwan (2000) explains that gender was brought to the forefront in the 1990s in South Africa, firstly, as a result of women of the ANC through the 1980s and the influence this had on intellectual discussions about the differential impact of apartheid on men and women and, secondly, because of the potential of a new constitution in bringing women's concerns to the table and the activities of ANC women activists.

These factors contributed to a commitment from South African women activists to ensure that gender equality was established as part of the new constitution and that 'mechanisms for mainstreaming gender equality' were put in place (Meer 2005). The Women's Movement is also conspicuous by its absence from official reports by the department. No formal interactions have been documented in any of the literature in the public domain. This critical element of the South African gender landscape must be re-ignited in some way in order to influence the current status quo.

The work of the Women's Movement in South Africa seems to have been slowed to the extent to which its clout can only be felt through marches. The everyday impact of the movement is absent from the operations of government. The inclusion of voices from the movement is absent in the reports availed for this article, indicating a lack of influence by the movement on the department's operations. Ideally, the Women's Movement should be holding the state accountable for the implementation of gender projects. By the same token, there are no sustained or documented efforts that assess how the department seeks to engage the NGOs working in the area of gender equality. Efforts by the department are currently limited to the bureaucracy. The department navigates this bureaucratic system through political relationships that require protocol implementation and thus its own levels of engagement are further politicised. The latter is constraining the department's ability to interact with the NGO sector but does not absolve the department from seeking collaborations with the civil society sector.

\section{Conclusion and recommendations}

This article analysed the role of an enabling environment in furthering the ends of gender mainstreaming in the Department of Public Service and Administration. Gumede (2008) in his assessment of the post-apartheid South African public service cited many policy implementation problems. The major focus of the article was on the role of an enabling environment in ensuring the successful implementation of the two key projects in the department, namely, the GMP and the 8-Point Principle Plan. The enabling environment was assessed in terms of the prioritisation and participation of SMS in driving the gender agenda in the department, the availing of resources (both human and financial) and the support of external structures for the operations of the Department of Public Service and Administration in mainstreaming gender. These criteria were measured through an analysis of reports generated for both projects, as well as through testimonies of relevant staff members in the Department of Public Service and Administration. In addition, experts were consulted regarding the creation of an enabling environment as it is related to external support, such 
as the National Gender Machinery, the Department of Women and the Commission for Gender Equality.

It is recommended that the Department of Public Service and Administration engages key organisations such as the Commission for Gender Equality, the Department of Women and the civil society sector in the development of a holistic strategy to address gender mainstreaming initiatives in the state. The projects in their current form cannot be effective and lack reach; in order to go to scale, an integrated strategy must be developed with the assistance of a revived National Gender Machinery.

This article reveals the major influence of political will in the bureaucratisation of gender mainstreaming and therefore a major influencer on the environment in which gender must be mainstreamed. Several role-players need to possess the political will to ensure that an enabling environment is created. Notably, the actions of an individual have an impact on the institutional reforms developed and created and vice versa as was discussed earlier. Political will is thus the most important factor in the development of an enabling environment and therefore creates the enabling environment through political buy-in.

\section{Acknowledgements}

The University of the Witwatersrand is acknowledged for the completion of the original $\mathrm{PhD}$ study in Political Science upon which this article is based.

\section{Competing interests}

The author has declared that no competing interests exist

\section{Author(s) contributions}

I declare that I am the sole author of this research article.

\section{Ethical considerations}

This article followed all ethical standards for a research without direct contact with human or animal subjects.

\section{Funding information}

This research received no specific grant from any funding agency in the public, commercial, or not-for-profit sectors.

\section{Data availability statement}

Data sharing is not applicable to this article as no new data were created or analysed in this study.

\section{Disclaimer}

The views and opinions expressed in this article are those of the authors and do not necessarily reflect the official policy or position of any affiliated agency of the authors.

\section{References}

Africa Regional Shadow Report, 2009, viewed 10 May 2017, from https://www. genderit.org/sites/default/upload/africa_regional_report__final.pdf.

Brynard, P.A., 2009, 'Mapping the factors that influence policy implementation', Journal of Public Administration and Governance 44, 557-577.

Development partnerships survey, 2014, Partner Feedback Report, Oxfam, viewed 10 July 2017, from https://www.oxfam.org/sites/www.oxfam.org/files/file_attachments/ story/oxfampartnerfeedbackreport05sept2014.pdf.

Dror, Y., 1975, Crazy states, Boston College International and comparative law review, viewed 01 June 2019, from https://www.scribd.com/document/178763696/ Crazy-States-By-Yehezkel-Dror-pdf.

Eyben, R., 2008, Conceptualising Pathways of Women's Empowerment. Pathways, Working Paper 1, viewed 10 October 2017, from http://rosalindeyben.net/ wpcontent/uploads/2014/05/Pathways_Working_Paper1.pdf.

Eysenck, H., 1954, The psychology of politics, viewed 17 November 2016, from http:// uspp.csbsju.edu/resources/preface.html.

Fester, G., 1998, 'Closing the gap - Activism and academia in South Africa: Towards a women's movement', in O. Nnaemeka (ed.), Sisterhood. Feminisms \& power. From Africa to the diaspora, pp. 18-23, Africa World Press Inc., Trenton, NJ.

First Inaugural Gender Indaba Report, 2008, viewed 13 December 2016, from http:// www.dpsa.gov.za/dpsa2g/documents/ee/Gender $\% 20$ Indaba $\% 20$ Report $\% 20$ 2008.pdf.

Geisler, G., 2000, 'Parliament is another terrain of struggle: Women, men and politics in South Africa', The Journal of Modern African Studies 38(4), 605-630. https:// doi.org/10.1017/S0022278X00003372

Giacchino, S. \& Kakabadse, A., 2003, 'Successful policy implementation: The route to building self-confident government', International Review of Administrative Sciences 69(2), 139-160. https://doi.org/10.1177/0020852303069002002

Goetz, A., (ed.), 1997, Getting institutions right for women in development, Zed Books, London.

Goggin, M.L., 1986, "The "too few cases/too many variables" problem in implementation research', The Western Political Quarterly 39(2), 328-347. https://doi.org/10.2307/448302

Gouws, A., 2005, The state of the national gender machinery, structural problems and personal politics, viewed 11 February 2019, from http://www.hsrcpress.ac.za.

Gumede, V., 2008, 'Public policy making in a post-apartheid South Africa: A preliminary perspective', Africanus 38(2), 7-23.

Hassim, S., 2003, 'The gender pact and democratic consolidation: Institutionalising gender equality in the South African state', Feminist Studies 29(3), 505-528.

Hassim, S., 2006, 'The virtuous circle of representation: Women in African parliaments', in G. Bauer \& H.E. Britton (eds.), Women in African parliaments, pp. 41-46, Lynne Rienner Publishers, London.

Kamuzora, P. \& Gilson L., 2007, 'Factors influencing implementation of the community health fund in Tanzania', Health Policy and Planning 22, 95-102. https://doi. org/10.1093/heapol/czm001

Kandiyoti, D., 2002, Bargaining with patriarchy, the women, gender and development reader, Zed Books, London.

Knafo, A. \& Schwartz, S.H., 2001, 'Value socialization in families of Israeli - born and soviet born adolescents in Israel,' Journal of Cross-Cultural Psychology 32(2), 213-228.

Leftwich, A., 1995, 'Bringing politics back in: Towards a model of the developmental state', Journal of Development Studies 31(3), 400-427. https://doi.org/10.1080/ 00220389508422370

Mannell, J.C., 2012, 'Practicing gender: Gender and development policy in South African organisations', Thesis submitted to the Gender Institute of the London School of Economics for the degree of Doctor of Philosophy, London, July 2012, viewed 02 July 2016, from http://etheses.Ise.ac.uk/567/1/Mannell_Practicing Gender_2012.pdf.

McEwan, C., 2000, Gender, geography and Empire. Victorian women travellers in West Africa, Ashgate Publishing, Aldershot.

Meer, S., 2005, 'Freedom for women: Mainstreaming gender in the South African liberation struggle and beyond', in F. Porter \& C. Sweetman (eds.), Mainstreaming gender in development, A critical review, pp. 36-45, Information Press, Oxford.

Mikkola, A. \& Miles, C.A., 2007, Development and gender equality: Consequences, causes, challenges and cures, Discussion paper No. 59, April 2007, viewed 01 May 2016, from https://ethesis.helsinki.fi/julkaisut/eri/hecer/disc/159/developm.pdf.

Persson, T. \& Tabellini, G., 2002, The Economic Effects of Constitutions. Paper for MIT press. viewed 10 April 2016, from https://www.bing.com/search?q=Persson+and +Tabellini\&form=PRHPC1\&src=IE11TR\&pc=HCTE.

Post, L.A., Raile, L.N. \& Raile, E.D., 2010, 'Defining political will', Politics \& Policy 38(4), 653-676.

Public Administration Leadership and Management Academy, 2013, Gender Masintreaming Final Evaluation Report (Internal document availed for the completion of the study).

Rao, A. \& Kelleher, D., 2005, 'Is There Life After Gender Mainstreaming?', in F. Porter \& C. Sweetman (eds.), Gender in Development, A Critical Review, pp. 57-69, Information Press, Oxford.

Rokeach, M., 1973, The nature of human values, Free Press, New York.

Schwartz, S.H., 1992, 'Universals in the content and structure of values: Theoretical advances and empirical tests in 20 countries', Advances in Experimental Social Psychology 25, 1-65. 
Schwartz, S.H., 1996, 'Value Priorities and Behavior: Applying a Theory of Integrated Value Systems', The Psychology of Values. The Ontario Symposium, 8. Lawrence Erlbaum Associates, Hillsdale, NJ.

Stone, D., 2001, Learning lessons, policy transfer and the international diffusion of policy ideas, Centre for the Study of Globalisation and Regionalisation (CSGR), University of Warwick, Coventry, Working Paper 69/01.

Tiessen, R., 2007, Everywhere/nowhere: Gender mainstreaming in development agencies, Kumarian Press, Bloomfield, CT.
Towards a 15 Year Review, 2009, viewed 11 June 2019, from https://www.dpme.gov.za. Tripp, A.M., Casimiro, I, Kwesiga, J.A. \& Mungwa, A., 2008, African women's movements: Transforming political landscapes, Cambridge University Press, Cambridge.

UN, 1979, Overview of CEDAW, New York, viewed 25 November 2019, from http:// www.un.org/womenwatch.

UN, 1995, Beijing platform for action, New York, viewed 01 November 2017, from http://www.un.org/womenwatch. 